\title{
LA ENSEÑANZA DE LA RELIGIÓN EN EL SISTEMA EDUCATIVO COSTARRICENSE: DIFICULTADES ACTUALES Y POSIBLES SOLUCIONES EN EL MARCO DE UNA SOCIEDAD PLURAL
}

Antonio Pizarro B. ${ }^{1}$

\section{Resumen}

Este artículo pretende ser una contribución al debate sobre la enseñanza de la religión en el sistema educativo costarricense. Este debate se ha hecho público a partir de la publicación el $1^{\circ}$ de mayo de 2005 de un Pronunciamiento del Consejo Universitario (CU) de la UNA. Primero se sitúa la enseñanza de la religión en el contexto concreto del país, se ofrece una definición pertinente de religión y sus implicaciones como premisas para comprender la polémica, se analizan las reacciones que el Comunicado ha generado y finalmente coincidiendo y apoyando al CU y a la EECR se proponen algunas medidas que podrían contribuir a encontrar soluciones inclusivas, democráticas, acordes con el pluralismo confesional efectivo de la sociedad costarricense.

\section{Abstract}

This article seeks to be a contribution to the debate on the teaching of the religion in the Costa Rican educational system. This debate has become public starting from the publication May $1^{\circ} 2005$ of a Pronouncement of the University Council (CU) of UNA (National University). First the teaching of the religion is located in the concrete context of the country. he offers a pertinent definition of religion and its implications like premises to understand the polemic, the reactions are analyzed that the Official statement has generated and finally coinciding and supporting the $\mathrm{CU}$ and the EECR (Ecumenical school of sciences of the religion) intends some measures that could contribute to find inclusive, democratic solutions, chords with the effective

1 Master of arts en historia por la Universidad Estatal de Voronezh (Rusia). Doctorando en la universidad de Sevilla (España). Profesor de la Universidad de Costa Rica, sede de Guanacaste (Liberia). 
confesional pluralism of the Costa Rican society.
Palabras claves: Religión. Educación religiosa. Pluralismo religioso. Relativismo cultural.

\section{INTRODUCCIÓN}

$\mathrm{L}$ a enseñanza de la religión "católica, apostólica y romana" es una pieza clave y "natural" del sistema educativo de nuestro país a nivel de primaria y secundaria. La legitimidad jurídica de esta característica de nuestra escuela descansa, en última instancia, en el carácter confesional del Estado costarricense tal como establece el Título VI (La Religión), Capítulo único, artículo 75 de la Constitución política de la República. Dicho artículo no hace sino continuar una tradición que se remonta al Pacto de la Concordia y que no se rompió ni siquiera en los peores momentos del enfrentamiento de la Iglesia con los liberales. La legitimidad social de esta norma era evidente para los constituyentes según se puede colegir de la invocación a Dios en la brevísima introducción que precede al articulado de la Carta Magna. En un país pequeño, con menos de un millón de habitantes donde, probablemente, todos habían sido bautizados según el rito católico la obviedad era, hasta cierto punto, lógica. Es de suponer que también pesaron en el ánimo de los miembros de la Asamblea Nacional Constituyente otras consideraciones como la tradición apuntada, el papel positivo jugado por la Iglesia Católica en el proceso de reforma al que ellos daban ahora rango de ley suprema, la fe personal de la mayoría por no decir la totalidad de ellos, etc.

El problema que se plantea a las constituciones es que no solo legitiman el statu quo sino que, además, condicionan la percepción y tratamiento macrojurídico de las realidades futuras de modo que si la formulación de la norma constitucional resulta excesivamente concreta, siendo la sociedad algo esencialmente dinámico, puede rápidamente quedar obsoleta y entorpecer el enfoque y la elaboración de respuestas adecuadas a las realidades emergentes. Por supuesto que los textos constitucionales prevén la posibilidad y los mecanismos para hacer reformas, adiciones, ampliaciones, etc. Ahí está la Constitución de los Estados Unidos de Norteamérica como ejemplo paradigmático de enmiendas constitucionales. El propio artículo 75 de nuestra Carta Magna fue modificado el 6 de junio de 1975 aunque sin alterar el sentido básico que poseía desde 1949. Y esa es, a nuestro juicio, una de las claves para comprender el asunto de que trata este artículo. 
Veamos. Si en 1949 Costa Rica era, forzando un poco las cosas, desde el punto de vista confesional una sociedad homogénea, medio siglo después y sobre todo a partir de la década de los setenta, la situación es sensiblemente otra. La aparición y difusión, merced en buena medida a una agresiva campaña de proselitismo, del movimiento fundamentalista neoprotestante, ha generado una diversidad confesional extraordinaria para un país tan pequeño como Costa Rica*. El panorama se complica con la presencia de un amplio sector de católicos nominales instalados en la indiferencia y de un grupo ciertamente minoritario identificado por la increencia (ateos, agnósticos y otros)**. Para estos últimos, la cuestión no es de libertad de culto o de conciencia, como se dice a veces y establece la Constitución, sino de libertad de pensamiento. En este caso, aunque se pueda invocar el amparo constitucional de los artículos 28 y 29 , y en el de los que profesan otras religiones y creencias distintas a la oficial, la concesión del mencionado artículo 75, la situación resulta manifiestamente lesiva si se considera que los derechos y garantías individuales deben ser objeto de respeto escrupuloso para todos y cada uno de los miembros de la sociedad independientemente de su ideología, sexo, raza, etc. La traducción de la confesionalidad del Estado al ámbito educativo permitirá más adelante ilustrar la afirmación anterior.

En resumen, se puede decir que la enseñanza de la religión "católica, apostólica y romana" bajo el nombre genérico y difuso de educación religiosa en las escuelas del país no responde a las mutaciones que en materia confesional ha experimentado la sociedad costarricense en el último medio siglo.

Antes de abordar la cuestión de la enseñanza de la religión, de los posibles enfoques apropiados para hacerlo, de los agentes idóneos para realizar esa labor por encargo del Estado y otras relacionadas con la polémica que ha motivado este artículo, resulta conveniente precisar algunos tópicos y conceptos de acuerdo con el estado actual de los conocimientos científicos. Y lo más lógico parece ser empezar por el concepto de religión.

\footnotetext{
* Este fenómeno afecta de forma desigual los distintos ámbitos de la sociedad. Por ejemplo, a nivel de convivencia las conversiones relativamente masivas al movimiento cristiano sectario ha afectado las familias generando disensión, a las comunidades incidiendo de forma directa en una serie de tradiciones y festividades populares relacionadas con el predominio ayer indiscutido del catolicismo, etc.

** Como ilustración se pueden citar los datos que da Picado G. M. (2205): 230 asociaciones de congregaciones protestantes en el 2001; un colegio y 20 locales de grupos no católicos en Costa de Pájaros. En Los Guido de Desamparados a un observador desprevenido le asombrará la cantidad de "iglesias evangélicas" situadas en la calle principal de este populoso suburbio capitalino. Las últimas ediciones del conocido Almanaque Mundial sitúan la población de católicos costarricenses alrededor de un $84 \%$. Según la última encuesta de la Escuela de Matemáticas de la UCR hecha pública a finales de julio del 2005 los católicos practicantes han disminuido de un $53,8 \%$ en el año 2000 a un $43,8 \%$ en este año mientras que un 10\% declara no tener religión (Telenoticias del 22/07/05 edición del mediodía).
} 


\section{SOBRE EL CONCEPTO DE RELIGIÓN}

"La religión es desde el comienzo una conciencia de lo transcendental proveniente de la necesidad real". K. Marx.

En un documental presentado por un canal de pago sobre la momia de Lenin en abril del 2005, se aseguraba que el fundador del Estado soviético fue el centro de una religión en una sociedad que había querido suprimir la religión. El propio marxismo, base ideológica más o menos problemática de los regímenes llamados de "socialismo real" ha sido calificado en ocasiones de religión. Por otra parte, el diputado Carlos Avendaño, en su personal polémica con V. de la Cruz (La Nación -en adelante LN-, 20/04/05 p. 34A.) afirma que el cristianismo no es una religión. ¿A qué se debe que unos científicos califiquen de religioso un fenómeno que obviamente no lo era y un pastor protestante niegue que la suya sea una religión? Dejando de lado la intencionalidad subyacente en estas afirmaciones es evidente que en ambos casos existe una nada inocente confusión sobre lo que es la religión. Y tratándose de un fenómeno de tanta trascendencia social es preciso recordar que la Antropología, Sociología, Historia y Filosofía de la Religión, tras arduos estudios, han logrado importantes aproximaciones para definir y caracterizar el fenómeno religioso y esos avances de la ciencia no pueden ser ignorados en una discusión seria. Obviamente la propia complejidad del material fenomenológico religioso, su naturaleza dinámica, las implicaciones omnímodas de la religión a nivel social e individual y otros posibles factores dificultan un consenso amplio sobre temas como la especificidad, la esencia, la delimitación de lo religioso, etc.

Esta problematicidad intrínseca ha vuelto cautelosos a los estudiosos de la religión y no pocos se inclinan por limitar el análisis al aspecto fenomenológico o, a lo sumo, operar con definiciones mínimas. Así, Max Weber (1977, p. 328) cuya contribución es imprescindible en cualquier estudio de la religión, aseguró expresamente que su Sociología no versaba sobre la "esencia" de la religión sino sobre la "acción comunitaria" que ella genera. Mircea Elíade (1956/1974, pp. 23-64), autoridad indiscutible para comprender el fenómeno religioso, buscando un común denominador a tan abigarrada manifestación humana, lo encontró sobre todo en las manifestaciones o experiencias de lo sagrado en el mundo. A Leszek Kolakowsky (1985, p. 12) le parece que Elíade captó lo peculiar y constitutivo del fenómeno religioso y parte de esta "definición suficiente" para ofrecer una serie de reflexiones indispensables 
por el punto de vista que adopta. Sin embargo, el ámbito de lo sagrado (que se opone a lo profano) puede resultar muy amplio ! a veces, ambiguo. Por esta razón algunos estudiosos de la religión, al menos desde Rudolf Otto (1917/ 1925) hasta Gustavo Bueno (1996), sostienen que el núcleo del fenómeno religioso es lo numinoso o el numen. Para el ateísmo marxista (Lenin, 1915 y Engels, F. 1977, p. 328) la causa de la aparición del fenómeno religioso es de naturaleza gnoseológica. De allí que la religión sea una aprehensión tergiversada de la realidad, un contenido fantástico de la conciencia cuyos referentes ontológicos en última instancia, son las fuerzas naturales y sociales reales, terrenales que revistiendo la forma de poderes sobrenaturales, condicionan y/o dominan la vida del ser humano. B. Russell (1912/1973, pp. 829-845), eximio filósofo agnóstico consideraba que lo peculiar de las religiones, tal como históricamente se han dado, es el dogma y eso les confería el carácter negativo que tienen desde su punto de vista. Un señalado representante del pensamiento posmoderno, Georges Bataille (1981) identifica la religión con el gasto improductivo, según él, una esfera completamente contraria a la economía y el orden productivo. En la más pura tradición del irracionalismo contemporáneo el pensador francés asegura que el ser humano se humaniza cuando trasciende la conciencia racional y utilitaria; es decir, cuando se sitúa en el ámbito de la religión (cfr.p. 60). Finalmente el teólogo Amando Robles (2001) en un ensayo relativamente reciente, único en su género en nuestro medio intelectual, reflexionando sobre la crisis que aqueja al cristianismo y a la religión en general como consecuencia de la secularización y de la llamada so. ciedad del conocimiento, defiende que lo auténtico de la religión y que, de un modo u otro ha estado presente siempre, lo que puełe salvarla de esta crisis y con lo que identifica su futuro es lo que él denomina el "conocimiento silencioso".

Es posible continuar una lista interminable de definiciones y perspectivas sobre la religión que acabaría por desanimar a cualquiera sobre las posibilidades de saber qué es realmente la religión; pero lo dicho hasta ahora es suficiente para probar que nos encontramos ante una parcela de la cultura polémica par excellence y que prácticamente ninguna definición escapa a la controversia. Se comprende entonces el escepticismo radical de los redactores de la Enciclopedia Encarta 2004, página 1, Introducción del artículo "Religión" cuando afirman que "es imposible encontrar una definición satisfactoria de religión".

No obstante este desalentador panorama, resulta ineludible convenir en alguna definición/caracterización operativa de la religión que permita contextualizar los términos y el sentido de la propuesta que aquí se hace. Aún a 
riesgo de parecer ecléctico en el sentido negativo de adoptar una posición cómoda, no comprometida, habría que decir que cada una de las aproximaciones aquí mencionadas casi al azar y otras conocidas (y hasta me atrevería a decir que en su conjunto también las no conocidas), tienen su parte de razón. Lo que se destaca en cada caso es lo que se considera axial, pero ningún estudio serio ignora los otros aspectos que, por lo demás, son obvios en el material fenomenológico. Esta diversidad (riqueza) de conceptualizaciones facilita una síntesis comprehensiva que debe satisfacer una serie de requisitos epistemológicos. En efecto, cualquier definición operativa de la religión debe aludir en primer lugar a "la cuestión que representa la clave para una comprensión del hecho religioso: su consideración genético-causal" (Puente Ojea, G. 1995, p. 36). Es preciso además referirse al material fenomenológico (discurso, conducta, organizaciones e instituciones), apuntar a las relaciones sociedad-religión e incluir las funciones que desempeña la religión a nivel individual y colectivo, etc.

Si nos atenemos a los requisitos mínimos apuntados, habría que empezar por establecer que lo que denominamos religión abarca al menos cuatro o cinco aspectos básicos; a saber:

A) En primer lugar, la religión constituye un peculiar desdoblamiento o escisión metafísica de la realidad en virtud del cual a la realidad material, natural o accesible a los sentidos se sobrepone jerárquicamente otra realidad inmaterial, sobrenatural o suprasensible. El estatus y la consistencia de esta segunda realidad no son algo unívoco y varían desde el sutil dharma (orden cósmico moral) del budismo hasta el vigoroso antropomorfismo del Dios personal en los monoteísmos del Libro. En última instancia. este desdoblamiento genera. exige de quien comparte la idea de la dualidad del Ser, la creencia en unos entes sobrenaturales -dioses, espíritus, fuerzas, númenes, etc..- que, de un modo u otro, interfieren en el universo y en la vida del hombre.

B) La aprehensión genuina de esta realidad heterónoma se realiza por procedimientos distintos a los que utilizamos en el conocimiento de la realidad natural ! giran todos alrededor del concepto de fe. No es que se prescinda del ejercicio intelectual, racional, para captar y comunicarse con lo sobrenatural, salvo en el caso, quizá, de la experiencia mística si hemos de creer a los que dan cuenta de ella (y aún en ese caso no se puede eludir el discurso analógico como certificará cualquiera que haya leído o lea a la famosa mística abulense Teresa de Cepeda y Ahumada). 
La peculiaridad de la intelección religiosa reside que sólo es posible desde y a través del prisma de la fe. Dicho pues brevemente, la religión es la fe en entes sobrenaturales, sean estos dioses, espíritus, fuerzas, orden cósmico, etc. A partir de esta premisa resulta inevitable indagar, comprender, hacer conocer a los que comparten una determinada fe, especular en la medida en que la comunicación entre los dos mundos se sustrae a las reglas que rigen esa misma actividad en la vida cotidiana, "teorizar" en suma, sobre la naturaleza de esos entes espirituales, su relación con el mundo y el hombre y viceversa. Para que nos entendamos: es preciso elaborar una teología. Esa teología, por muy rudimentaria que sea, entraña y/o prescribe ciertas formas de acceder a la realidad trascendente (culto), reglas y normas de comportamiento (ritos) adecuadas para relacionarse con ese reino sobrenatural.

C) De lo apuntado hasta ahora se deduce que el conjunto de los adeptos a cualquier sistema religioso se vinculan o atan entre sí y con el (los) objeto/s de su fe* por medio de un corpus ideas, afirmaciones, creencias, etc. reveladas o no, conductas y organizaciones que los identifican y estructuran necesariamente como una "sociedad" o comunidad-ecclesia-particular. A lo interno, esa comunidad aparece escindida por una peculiar división social y jerárquica de funciones entre una masa de creyentes más o menos anónimos (laicos) y un grupo minoritario de administradores de la fe (chamanes, clero, teólogos y otros) que se asignan un papel carismático o rutinizado de liderazgo y mediación entre aquellos y la divinidad o realidad trascendente. De este modo, aunque la religión tiene por objeto algo que está "más allá" de la experiencia racional habitual de este mundo (incluso en el caso del mana) los que la comparten están situados (viven) "acá" y en sus relaciones con la otra realidad observan determinados comportamientos ("acción comunitaria") que indeclinablemente se ritualizan en un cierto orden litúrgico. Alrededor de liturgia, ritos y culto, privados o públicos, los adeptos a una fe necesariamente se organizan en instituciones en el más amplio sentido de la palabra y la presencia de la religión se vuelve corpórea, deviene poder en el conjunto de la sociedad. La importancia de este aspecto es crucial, al punto que Cicerón (Lib. II, 28/72, p. 206) derivaba de su ejercicio el concepto de religión.

* Religión: del latín religare, o sea, ligar, atar como se desprende de Lucrecio. 
D) Finalmente, en la medida que la religión implica una ligazón o relación compleja entre divinidad y creyente*, engendra en éste una forma peculiar de estar en el mundo y enfrentarlo y una cierta psicología típicamente religiosa en la que la experiencia numinosa o de lo sagrado es tenida por la más genuina expresión. Estos cuatro grandes aspectos -creencia en la existencia de una realidad suprasensible, discurso/conductas, instituciones y psicología religiosa- se materializan en determinadas estructuras o realidades reconocibles que hacen de la religión, como no podía ser menos en sociedad, un fenómeno extremadamente funcional. Dicho de otro modo, la religión cumple una serie de funciones identificables a nivel social e individual.

Empecemos por estas últimas. Como se decía anteriormente, la religión provoca en quien la comparte una determinada forma de estar en el mundo y proporciona unos contenidos que al ser asumidos proveen al individuo de una concepción del mundo que supera (y estructura) la espontánea percepción del "estar aquí". Esta Weltanschauung como la llaman los alemanes, da sentido a la existencia del ser humano y le sirve de referencia ética general. Más allá, en un proceso de interacción dialéctica de los planos individual y colectivo, la religión

"confiere un significado particular al orden social existente, así como al orden natural y a los hechos y condiciones típicos de la existencia humana, dando en los tres casos interpretaciones de acontecimientos colectivos, individuales y físicos, capaces de aparecer como legítimas o justas o razonables, e incluso racionales en el marco de ese orden, incluyendo los acontecimientos que el sujeto experimenta en el orden terreno, materialmente sensible, como acontecimientos irracionales o injustos o terriblemente casuales como el sufrimiento, las desigualdades sociales, los desastres naturales, la violencia, etc.". Gallino, L. (2001, pp. 761-762).

Dicho brevemente, en el plano social la religión ha sacralizado, justificado, legitimado o contemporizado con las distintas sociedades en las que se ha desenvuelto. Desde una situación de privilegio ha contribuido en distintos grados a generar cohesión ideológica al organismo social, consenso y

\footnotetext{
* La EECR. por ejemplo, realiza esfuerzos dignos de la mayor atención, para superar la "racionalización” y apología de la injusticia por parte del discurso religioso tradicional. Cfr. Molina, X. 2004, 6.
} 
obediencia civil. En sociedades de clases, estas funciones de la religión tienen un carácter profundamente negativo porque, al otorgar legitimación divina a un régimen injusto per se, impiden la superación estructural de las asimetrías sociales. Sin embargo, se ha argumentado que la religión puede desempeñar el papel inverso, de impugnadora de un régimen social y se cita el ejemplo de la ética protestante en los orígenes del capitalismo (Weber) o de la Teología de la Liberación*. Por otra parte, en las relaciones entre distintas sociedades, culturas y civilizaciones la religión ha sido un factor especialmente nefasto como nos recordaba J. Saramago en "El factor Dios".

Otro frente de controversia tan importante o más que los que acabamos de mencionar porque atañe a la llamada cuestión de la verdad de la religión, es la incapacidad del discurso religioso para entablar un diálogo de validez intersubjetiva que responda a los requisitos de racionalidad. $Y$ esto aún en el caso de que interpretemos la razón no en el sentido estrecho de Weber, sino en el amplio de facultad derivada del correcto o normal funcionamiento de las propiedades físico-síquicas del cerebro (Sánchez de las Matas, M.)*. La imposibilidad de conciliar la existencia del mal con los atributos de Dios puede ilustrar lo que se acaba de afirmar. La admirable proeza de Leibniz (La Teodi-

* "La mente humana carece de medios cognoscitivos para registrar objetivamente hechos o entes situados fuera del reino de la experiencia”. Puente Ojea, G. 1997, p. 68.
Habria que empezar por establecer que lo que denominamos religión abarca al menos cuatro o cinco aspectos básicos; a saber: A) en primer lugar, la religión constituye un peculiar desdoblamiento o escisión metafísica de la realidad en virtud del cual a la realidad material, natural o accesible a los sentidos se sobrepone jerárquicamente otra realidad inmaterial, sobrenatural o suprasensible. El estatus y la consistencia de esta segunda realidad no son algo unívoco y varian desde el sutil charma (orden cosmico moral) del budismo hasta el vigoroso antropomorfismo del Dios personal en los monoteismos del Libro. La aprehension genuina de esta realidad heterónoma se realiza por procedimientos distintos a los que utilizamos en el conocimiento de la realidad natural y giran todos alrededor del concepto de fe. 
cea, 1710) no sólo no resolvió la cuestión, sino que incluso la llevó a un callejón sin salida. Así lo demuestra Sánchez de las Matas, M. (2004). En un artículo posterior (en prensa) nos ofrece una línea argumental que con rigor lógico nos lleva a convenir que la imperfección estaba en el mismo Dios. Estas y otras objeciones inducen a pensar que más que corregir o actualizar a Leibniz habría que desistir de todo proyecto de construir una "Teodicea imposible" (cfr. 1994, Madrid, Trotta). En fin, la naturaleza aporética del discurso teísta y la dualidad de funciones (negativas) de la religión, dentro de la sociedad concreta sobre la que ella se estructura como forma de conciencia social y en las relaciones interculturales, nos permiten abordar el carácter polémico de la religión.

\section{LA NATURALEZA POLÉMICA DE LA RELIGIÓN}

La religión tal y como ha sido expuesta hasta aquí es un fenómeno controvertido, difícil de tratar y, al mismo tiempo, en tanto objeto de estudio, apasionante como pocos. Aunque el registro histórico limitado a los restos materiales de la cultura (RMC) es muy pobre, con ayuda del material etnográfico disponible y en parte extrapolando, es posible inferir que, desde su aparición allá en el Paleölítico Medio el fenómeno religioso no debe haber estado exento de polémica. En el marco de sociedades ágrafas, con la aparición de grupos especializados -los chamanes, brujos, curanderos, etc.- que monopolizaban el conocimiento en general y el religioso (mágico) en particular, confiriéndole un carácter esotérico, las discusiones deben haberse limitado al estrecho círculo de los iniciados. Ciertamente, la situación apenas mejoró con el nacimiento de la civilización, aunque en esta nueva etapa de la historia de la humanidad asistimos a una relativa ampliación de la capa social de lo que hoy llamamos intelectuales y la controversia en materia religiosa se vio enriquecida con el surgimiento del pensamiento francamente disidente. Es así como en el Antiguo Egipto dos monumentos literarios, La canción del arpista y el Diálogo de un desengañado con su alma demuestran que, aún bajo el predominio absoluto de la religión el agnosticismo, el materialismo filosófico y en cierto modo el ateísmo habían conseguido hacerse escuchar y, lo que es más importante, dejar constancia de sus opiniones, de su discrepancia. Otro tanto se puede decir del Diálogo del amo con su esclavo acerca del sentido de la vida; obra literaria de la Antigua Babilonia que, en la humilde opinión del que esto escribe, debería considerarse como el primer documento filosófico de la historia. De todos modos, la magnitud de la controversia escapa a nuestra comprensión porque el pensamiento alternativo de aquella época se ha 
conservado muy mal, incluso en las Antiguas Grecia y Roma como se puede convencer cualquiera leyendo, por poner un caso, el admirable tratado de Cicerón (2000).

Tras el severo paréntesis de la Edad Media (de todas maneras no cabe olvidar la discusión entre nominalistas y realistas, sobre todo por sus implicaciones) la controversia no ha hecho si no aumentar. Como es sabido, a partir del Renacimiento, particularmente en Europa, toma cuerpo un poderoso proceso de secularización, que todavía no ha concluido, y que se manifiesta en una progresiva reducción del condicionamiento religioso sobre la conducta en general y en la comprensión del Universo, la sociedad y el Hombre. Los enfoques e interpretaciones de este fenómeno son diversos, pero a efectos de lo que aquí interesa basta con constatar su existencia. Si partimos de la situación ideal de predominio absoluto de la religión sobre la conciencia de los hombres y mujeres del pasado (el pensamiento disidente en tanto marginal era la excepción que confirmaba la regla) el mencionado proceso de secularización con todas las objeciones que se le puedan hacer, entraña una crisis del pensamiento religioso.

En cierto modo, el divorcio entre lo religioso y lo no religioso tuvo su punto culminante en la institucionalización u oficialización del ateísmo durante el siglo pasado en las sociedades llamadas socialistas, y en los movimientos de liberación femenina, sexual, social, etc. que sacudieron el siglo XX. Precisamente esta coyuntura generó o contribuyó a generar reacciones como la reafirmación religiosa de la que es parte el fundamentalismo y/o integrismo (Kepel, G. 1991), la búsqueda de respuestas positivas desde la fe a los desafíos que en materia social planteaba la increencia (piénsese en la Teología de la Liberación), propuestas como el ecumenismo, etc. En el mundo desarrollado occidental se llegó, según algunos expertos, a una tregua entre ciencia y religión, porque cada parte reconoció que trabajaba en un ámbito propio y no debía invadir el de la otra. Este principio parece ser uno de los pilares de la argumentación del Papa Juan Pablo II en su documento Fides et ratio (1998). Obviamente, sólo parece porque se da por sentada y se propugna la supremacía de la fe frente a la razón como corrobora otro documento pontificio anterior (1986) que lleva por título Dominum et vivificantem. Pero ni la tregua, ni la "revancha de Dios" han conseguido parar el proceso de secularización tal como constatan diversos estudios, encuestas, observaciones eruditas o cotidianas, etc.*

\footnotetext{
* En este punto disentimos de la opinión de Berger, P(LN/01/05/05. p. 42A) para quien "la era moderna [se refiere a la contemporánea -AP] es tan religiosa como cualquier época histórica y en algunos lugares lo es más". Según datos de la Britannica Book of the Year (1990) que cita Kottak. C. Ph. 1999. p. 362, los que no tienen religión
} 
Costa Rica durante las épocas moderna y contemporánea no se ha mantenido al margen de la polémica que aquí sumariamente se ha reseñado. Ya desde la época colonial los indígenas de Talamanca, frente a la imposición del cristianismo, defendieron su diversidad cultural y en alguna ocasión cierto cacique planteó el respeto de la religión autóctona como requisito para la convivencia pacífica. Pero Talamanca era una zona marginal y su lucha por la pluralidad religiosa no se inscribe en el proceso de secularización. Dentro de la sociedad colonial apareció un curioso fenómeno de relajación en el cumplimiento de las obligaciones religiosas por parte de nuestros antepasados criollos/mestizos. Se podría decir que se dio incluso cierto indiferentismo religioso. Las explicaciones que se han propuesto, alguna de ellas peregrina, podrían contextualizarse mejor si atendemos, para apuntar uno de los factores, a informes contemporáneos como el de Cortés y Larraz para el norte del reino de Guatemala donde se denuncian situaciones similares. Pero no será sino después de la Independencia que se planteará la cuestión de las relaciones entre el Estado y la Iglesia Católica. Como es sabido, los enfrentamientos más importantes entre religión y laicismo se dieron en nuestro país durante el siglo XIX y no parece que con posterioridad nuestra sociedad haya experimentado una secularización similar en profundidad y extensión a la europea*. Sea como fuere, dentro de un modesto proceso de secularización, la incidencia de diversos factores, algunos de los cuales ya se han mencionado, ha modificado seriamente la posición de la Iglesia Católica en nuestra sociedad, mientras se mantiene el principio constitucional de confesionalidad del Estado.

Ante esta situación, algunas preguntas parecen obvias: ¿Qué mutaciones en la composición confesional de la sociedad costarricense serán necesarias para que el Estado se decida a modificar el artículo 75 de nuestra Constitución política? Y si bien, no se trata de cuestionar directamente la existencia de una religión oficial, no es menos cierto que el Estado debe garantizar a ese amplio sector que no comparte el catolicismo el ejercicio pleno de sus derechos, garantías y libertades, sobre todo en materia de conciencia, que les son inalienables en su condición de costarricenses, independientemente de su adscripción religiosa. Pero más allá del respeto a las minorías religiosas, con una visión de futuro habría que revisar a la luz de la diversidad de conciencia y pensamiento

constituyen poco más del $16 \%$ de la población mundial. Si se considera que ese porcentaje es sólo un punto inferior al de los creyentes musulmanes se verá que hablar de la secularización y su corolario la increencia como de un fenómeno marginal no resiste a la crítica seria. Véase: Marlasca L. A. 1994, 32.

* En charla personal con el profesor Iván Molina él me aseguró que, guardando las distancias y proporciones, tal proceso sí se da en Costa Rica. En un artículo que explora la difusión del ateísmo y el descreimiento en San José a principios del siglo XX llega a una conclusión que no deja de ser sorprendente. Él llega a establecer que para esa época "la secularización social... se había extendido de la cima a la base de la jerarquía social y a lo largo de muy diversas categorías ocupacionales" (Molina. J. I. 2004, p. 48.) 
que ahora reconocemos, las obligaciones del Estado en materia religiosa. Habría que preguntarse (una de las cualidades específicamente humanas de nuestra psique es el poder de anticipación) si no es hora ya de superar el estrecho margen de una confesión por muy numerosa y entrañable que sea* y ofrecer en las escuelas estatales a las nuevas generaciones que les tocará desenvolverse en un mundo tremendamente globalizado y dominado por la diversidad cultural y religiosa una perspectiva de lo religioso que trascienda (sin abandonar) su concepción doméstica. Nuestra época llamada con un exceso de optimismo la de la sociedad del conocimiento** nos obligará a convivir y interactuar dialécticamente con distintas culturas (ya lo hace a través de los medios de comunicación y de los procesos migratorios) y deberíamos emprender un plan estratégico similar al que se está poniendo en marcha en materia de ciencia y tecnología a fin de prepararnos para ese cambio.

Si no nos preparamos, sucederá lo que ha pasado hasta ahora con sociedades menos dinámicas o situadas por las circunstancias históricas en situaciones de desventaja: que nuestros valores culturales sucumbirán ante el empuje arrollador de otras culturas respaldadas por el poderío económico y social. La endeblez de nuestras identidades nacionales tiene que ver con el carácter periférico de nuestras estructuras socioeconómicas. El poder de anticipación nos puede ayudar a defender mejor los elementos positivos de nuestro modo de ser y así encarar con confianza la inevitable síntesis a la que nos veremos abocados como ha sucedido siempre con los que han habitado este territorio desde hace unos 11000 años y con la humanidad en general desde que los primeros colectivos humanos abandonaron su patria africana ancestral para desparramarse por todo el planeta.

\section{LA POLÉMICA SOBRE LA ENSEÑANZA DEL CATOLICISMO EN LA ESCUELA COSTARRICENSE: PROPUESTAS PARA UNA SOLU- CIÓN DEMOCRÁTICA EN UNA SOCIEDAD PLURAL}

“...pues en lo que toca a la razón, siendo, como es, la única cosa que nos hace hombres y nos distingue de los animales, quiero creer que está entera en cada uno de nosotros". Descartes.

El $1^{\circ}$ de mayo del 2005, el Consejo Universitario (CU) de la UNA hizo público un Pronunciamiento "sobre la manera en que se organiza, dirige y

\footnotetext{
* Según los datos que Kottak, C. Ph. (1999) ibídem ese año de 1990 los católicos no llegaban a un 20\% de la población total del planeta. No dispongo en este momento de datos mús recientes pero el objetivo es dar una idea aproximada y nada más.

** Según CNN en la ciudad de Nueva York hay más conexiones a internet que en todo el continente africano.
} 
orienta la educación religiosa en el Sistema Educativo Costarricense" (L/N, p. 17 Viva). Partiendo de los principios y ejes sobre los que gira el quehacer de la UNA con miras a alcanzar una visión integral, holística del ser humano, el CU expresa su profunda preocupación por la forma en que se ha organizado y practica la educación religiosa en nuestras escuelas. Los orígenes del conflicto que ahora sale a la luz pública, se remontan a una época en que la propia UNA nacía. En efecto, por aquellos años el Estado costarricense a través del artículo 34 del Reglamento de la Ley de Carrera Docente delegó con carácter de exclusividad en la Iglesia Católica la organización y selección de los agentes idóneos para la enseñanza de la religión en el sistema educativo. El hecho de que un Estado tan comprometido con la educación de sus ciudadanos al punto de ser calificado de Estado Docente (Dengo, M. E. 2002, p.18), haya renunciado a una de sus potestades "naturales" más importantes es digno de reflexión aunque en el contexto de un Estado confesional pueda resultar lógico. Un cuarto de siglo más tarde, en posesión de los privilegios en materia educativa y otros, la Iglesia Católica da un paso más en la dirección de controlar completamente la formación religiosa en las etapas cruciales del desarrollo humano* y emite un Reglamento sobre el otorgamiento y revocatoria de la llamada Missio Canonica. Además de las prerrogativas que le concedían las leyes de 1972 y 1975, ahora la Conferencia episcopal decreta, con la aquiescencia de las instancias estatales correspondientes, que sólo los egresados de su universidad privada u otras a las que ella dé su fiat podrán impartir la enseñanza religiosa en las instituciones educativas públicas. Obviamente nos encontramos ante una situación anómala, una peligrosa extralimitación de una "institución privada" (Tagliviani, A. A. LN/ 17/04/05, p. 31A) usurpando las competencias de un Estado soberano. ¿Por qué no se impugnó en aquella ocasión este evidente desafuero?

Vistas las consecuencias de aquel giro, salen ahora el CU de la UNA y la EECR a exigir con exquisito respeto una revisión de la situación creada. Sus demandas y propuestas en el apartado de "Acuerda" de dicho Pronunciamiento son impecables y quien esto escribe manifiesta su total apoyo a dichos acuerdos. Quizá se eche en falta desde el "enfoque holístico" la inclusión de la indiferencia religiosa e, incluso, la increencia como actitudes dignas de similar respeto y apoyo pero parece que el marco de referencia que sustentan los miembros de la EECR no contempla esa opción. Así se deduce también de

\footnotetext{
* "La religión no podrá nunca ocupar en el fondo del corazón el lugar tranquilo que le corresponde, si su idea fundamental no ha sido inculcada en la primera infancia“. Herbart. J.F.
} 
los programas de extensión que ha puesto en marcha la Escuela, ahora bajo la dirección de D. Francisco Mena. El programa Espiritualidad y valores "dirigido a adolescentes de secundaria que no cursan Religión" está animado por una vocación ecuménica que, al menos en su intención (desconozco los contenidos concretos), difiere notablemente de los programas oficiales de la asignatura "Educación religiosa" 2005*. Esta iniciativa es digna de aplauso pues, como en la misma nota informativa se aclara, los estudiantes que no reciben religión "representan alrededor de un 30\% de la población estudiantil". (Barantes C. V. J. 2005).

Ante esta actitud reivindicadora pero dialogante y respetuosa de la UNA, un miembro de la misma EECR, el apreciado historiador Miguel Picado ha reaccionado de manera airada preguntando si lo que buscan sus colegas es una enseñanza aconfesional de la religión como paso previo a la total supresión de esta asignatura en la escuela pública. La falta de espacio impide entrar a analizar en detalle este artículo, pero de su lectura desapasionada se infiere ira, se suscitan dudas sobre el modo de citar y no parecen pertinentes las objeciones**. La Iglesia Católica por su parte, en un comunicado de la Conferencia Episcopal del 16/06/05 rechazó las demandas y propuestas de la UNA, calificándolas de "particular punto de vista" viciado por un "enfoque unilateral". Al mismo tiempo esgrime las credenciales de su posición privilegiada: "los más preciados valores de la comunidad nacional, ...nuestras verdaderas raíces históricas y el significado de la iglesia católica en el establecimiento de la institucionalidad costarricense" (Extra, 17/06/05, p.4). Asegura haber sido "invitada" a encargarse de la educación religiosa de las nuevas generaciones e invocando a Jesucristo, declara que el derecho que se arrogó por el Reglamento del 30/11/01 es "irrenunciable". Finalmente, tratando de despejar algunas confusiones presumiblemente interesadas acerca de las intenciones y el alcance de sus reivindicaciones, la EECR, por ella misma (Extra 27/06/05) como por boca de su director (cfr. LN 17/06/05, p. 12A), han clarificado y puntualizado el sentido de sus demandas y propuestas. Mientras tanto, el MEP todavía no se ha pronunciado. Este es, a grandes rasgos, el conflicto planteado en

\footnotetext{
* Por ejemplo, la cita sobre el marco no confesional se refiere en el Pronunciamiento al enfoque metodológico de la EECR y no al tipo de enseñanza de la religión que se quiere implantar en las escuelas. Asimismo la afirmación de que la Iglesia católica desde sus orígenes, por deseo de su fundador, es independiente de los gobiernos no resiste ningún análisis histórico, etc.

** Esta no es una afirmación gratuita. Cualquiera que lea dichos programas puede comprobar que ni planteamiento, ni enfoque, ni contenidos prevén la posibilidad de un desarrollo ecuménico de la asignatura, ni siquiera en el marco de las distintas iglesias y confesiones cristianas. Por si quedaran dudas. la bibliografía del Programa las despeja definitivamente. Vale la pena destacar que este sesgo se da en el contexto de un papado, el de Juan Pablo II, que, como pocos ha tratado de poner en práctica una política de ecumenismo
} 
torno a la enseñanza de la religión en las escuelas primaria y secundaria de nuestro país y el estado de la cuestión en este momento. ¿Qué conclusiones se pueden sacar en esta coyuntura?

\section{CONCLUSIONES}

A partir de lo expuesto a lo largo de estas páginas parece oportuno hacer a modo de conclusiones, algunas propuestas:

a. Los privilegios de que goza la Iglesia Católica en todos los ámbitos de la vida nacional y particularmente en el de la educación estatal formal, privilegios de los que no gozan otras confesiones y, menos aún, la increencia, derivan en último análisis del carácter confesional del Estado costarricense. Por eso no se puede compartir la opinión del CU según la cual "el hecho mismo de que la Iglesia Católica sea la responsable de la educación religiosa no constituye el problema de fondo (Pronunciamiento, considerando 3j). Precisamente las "prácticas excluyentes y discriminatorias" denunciadas remiten con necesidad axiomática al principio constitucional aludido y su regulación jurídica, legal, que se remonta a la Ley $n^{\circ} .21$ del 08/11/1940, se desarrolla en sucesivos Decretos de 1975, 1992, 1983, 1985, 1994 y se prolonga hasta el polémico Reglamento de la "Missio Canonica". Dicho brevemente: el exclusivismo que practica la Iglesia Católica tiene cobertura legal. Eso no quiere decir que la modificación de la situación actual pase necesariamente por la derogación o reforma del artículo 75 de la Constitución de la República. Todo depende del desenlace que tenga el conflicto presente. Si las personas e instituciones afectadas directamente por la situación actual mantienen una actitud firme y coherente, si encuentran apoyo en la opinión pública y si la Iglesia Católica, pese a su rotunda negativa del 16/ 06 pasado se aviene a entablar un diálogo serio, se podría llegar a una solución que no cuestionara la confesionalidad del Estado. Aún así, de todas maneras, a la larga, si se mantienen las tendencias ideológicas apuntadas en la primera parte de este artículo y si el Estado costarricense sigue evolucionando en la dirección del pluralismo confesional e ideológico y el relativismo cultural, es previsible que el Estado confesional termine siendo impugnado.

b. A corto plazo parece pertinente asumir la recomendación del Comité de Derechos Humanos de la ONU al Estado costarricense en esta materia y 
poner en práctica las modificaciones necesarias en dos sentidos: en primer lugar, la de los agentes idóneos para impartir una asignatura -la Religión- con cargo a los presupuestos públicos en la escuela estatal; vale decir, pública. El sentido común aconseja que la aplicación de los requisitos del Reglamento de la Carrera Docente para otras asignaturas se aplique también en el caso de la Religión. El requisito de idoneidad confesional la Iglesia debe trasladarlo a los catequistas, pastores y al ámbito de reproducción que le es propio: la familia, los templos y el testimonio público. En segundo lugar el estatus de la asignatura de Religión en el currículo escolar. La asistencia a las clases de religión debe ser libre en el verdadero sentido de esta palabra; o sea, eliminando el requisito de solicitud de los padres con argumentación razonada para que sus hijos sean eximidos de esa asignatura. A estas alturas dicho requisito es un atavismo de los tiempos en que no ser católico era la excepción que confirmaba la regla. Pero incluso entonces con él se lesionaba el derecho de libertad de conciencia que la Constitución garantiza a todos y cada uno de los costarricenses. En su lugar, se podría incluir en los formularios de matrícula un espacio en el que los padres o encargados marquen con una equis (X) si facultan a sus hijos para que asistan a las clases de religión. En el nivel de Educación diversificada esa decisión se podría traspasar a los propios estudiantes como se hace en algunos países. La instrucción religiosa de los estudiantes no católicos, toda vez que el Estado costarricense se ha hecho cargo de una labor que, en rigor no compete al Estado actual, liberal, democrático, debe ser igualmente garantizada, atendiendo, por ejemplo, a un número crítico de alumnos de esta o aquella confesión en tal o cual escuela o colegio. Las dificultades para cumplir con esta obligación que aducía Miguel Picado en su crítica al Pronunciamiento del CU, no son consistentes. El Estado ha creado el problema, él debe adoptar las medidas para solucionarlo. Si partimos del supuesto, como hace la Iglesia Católica en su comunicado del 16 de junio, de que con la instrucción religiosa se pretende inculcar en los niños y jóvenes valores y virtudes morales, a los que, por el motivo que sea no reciban religión, se les debe ofrecer una alternativa como Ética o, mejor, Filosofía impartidas por “un profesorado muy competente y rigurosamente seleccionado mediante" los mecanismos que prevé la Ley de Carrera Docente e, incluso, "pruebas de suficiencia en pie de igualdad y con total imparcialidad" (Cfr. Puente Ojea, G. 1995, p. 392). 
c. "Un Estado confesional es un anacronismo" (Picado, M. 1989, p. 23). Así que cuando el Estado costarricense, como corresponde a un Estado de principios del siglo XXI, se abstenga (J. Habermas) de proporcionar visiones del mundo a sus ciudadanos, de recurrir a legitimaciones religiosas directas o indirectas y funde sus atestados y legitimidad en el ejercicio pleno, laico, político de la democracia; cuando "las instituciones religiosas [decidan] no depender del Estado para que llene los bancos de su templos" (Berger, P. L. 2005), cuando trono y altar ocupen los lugares que les ha asignado la evolución de la sociedad contemporánea, habrá que seguir enseñando la religión a las nuevas generaciones, porque la religión es un universal cultural cuyo conocimiento es un requisito indispensable para la formación del individuo. Pero la religión a secas no existe desde el punto de vista de una religión concreta. La enseñanza de la religión es siempre la enseñanza de alguna religión. En la escuela de un país islámico, con toda seguridad será el Islam, en Costa Rica es la enseñanza de la religión oficial: el catolicismo. Y en este sentido no existe realmente lo que llamamos educación religiosa sino catequesis. Paradójicamente y a pesar de las preguntas clave de Miguel Picado, la única enseñanza de la religión que, en rigor científico merece ese nombre es la enseñanza aconfesional de la religión. Eso sólo es posible en un Estado realmente democrático con "una escuela pública gratuita que imparta enseñanzas confesionalmente neutrales, que incluya en el estudio de la cultura los hechos religiosos como fenómenos históricos, así como los grandes debates científicos y filosóficos en torno a los mismos, con objetividad y sin intención proselitista" (Puente Ojea, G. Idem, p. 391). 


\section{REFERENCIAS}

Barrantes C., V. J. (2005). "Una teología al servicio de la gente”. CAMPUS/ Mayo 2005, p. 7Actualidad.

Bataille, G. (1981). Teoría de la religión. Madrid. Taurus.

Berger, P. L. (2005). "Pluralismo religioso en una era pluralista". La Nación. 01/05/ 05, p. 42A.

Bueno, G. (1996). El animal divino. Ensayo de una filosofía materialista de la religión. Oviedo (España). Pentalfa Ediciones (Grupo Helicón, s.a.).

Cicerón. (2000). Sobre la naturaleza de los dioses. Madrid. Editorial Gredos, s.a.

Consejo Universitario. (2005). Pronunciamiento de la Universidad Nacional sobre la manera en que se organiza, dirige y orienta la educación religiosa en el Sistema Educativo Costarricense. La Nación, 01/05/05, p. 17 Viva.

Dengo, M. E. (2002). Nuevos paradigmas para la educación. Colección Ideario XXI, $n^{\circ}$. 15. San José. EUNED.

Elíade, M. (1974). "Lo sagrado y lo profano: naturaleza de la religión (1956)". Tratado de historia de las religiones. Tomo I. Aproximaciones: estructura y morfología de lo sagrado. Pp. 23-64. Madrid. Ediciones Cristiandad.

Engels, F. Anti Düring. En: Obras (en ruso). Tomo 20. Moscú. Institut Marxizma leninizma.

E.E.C.R. (2005). "Recuperar el futuro". Diario Extra, 27/06/05, p. 9.

Gallino, L. (2001). Diccionario de Sociología. Madrid. Siglo XXI editores, s.a.

Golcher B., R. (2005). "Crece conflicto entre Iglesia Católica y UNA." La Nación, $17 / 06 / 05$, p. $12 \mathrm{~A}$.

Kepel, G. (1991). La revancha de Dios. Cristianos, judios y musulmanes a la reconquista del mundo. Madrid. Anaya \& Mario Muchnik.

Kolakowsky, L. (1985). Si Dios existe... Sobre Dios, el diablo, el pecado y otras preocupaciones de la llamada filosofía de la religión. Madrid. Editorial Tecnos, s.a.

Kottak, C. Ph. (1999). Antropología: una exploración de la diversidad humana. Con temas de cultura hispánica. Madrid. McGraw-Hill.

Lenin, V.I. (1915). Acerca de la Dialéctica. En: Cuadernos filosóficos. Obras completas (en ruso). Tomo 29, 5 a edición. Moscú. Politizdát.

Marlasca, L. A. et. al. (1994) Por Dios, contra Dios. San José, Guayacán, s.a.

MEP. (2005). Educación religiosa. III Ciclo. Programa de Estudios 2005.

MEP. (2005). Educación religiosa. Educación Diversificada. Programa de Estudios 2005.

Molina R., X. (2004). “Discursoreligioso perjudica a niñez”. CAMPUS/Mayo 2004, p. 6 Actualidad. 
Molina R., X. (2005). "UNA solicita al MEP cambios inmediatos". Enseñanza de la religión discriminatoria. CAMPUS/ Mayo 2005, p. 7 Actualidad.

Otto, R. (1925). Lo santo. Madrid. Revista de Occidente.

Picado, M, (1989). La iglesia costarricense: entre Dios y el César. San José. Editorial DEI.

Picado G., M. (2005). “¿Enseñanza aconfesional de la religión?” La Nación, 08/05/ 05, p. 28A.

Puente Ojea, G. (1995). Elogio del ateísmo. Los espejos de una ilusión. Madrid. Siglo XXI editores, s.a.

Puente Ojea, G. (1997). Ateísmo y religiosidad. Reflexiones sobre un debate. Madrid. Siglo XXI de España editores, s.a.

Robles, A. (2001). Repensar la religión. De la creencia al conocimiento. Heredia, C. R. EUNA.

Russell, B. (1912/1973). La esencia de la religión. En: Escritos básicos, 1903-1959. pp. 829-845. México, D.F. Aguilar Editor, s.a.

Sáenz V., G. (2005). "Se oponen a criterio de la UNA. Obispos dicen que ellos deben escoger profesores de religión". Diario Extra, 17/06/05, p. 4.

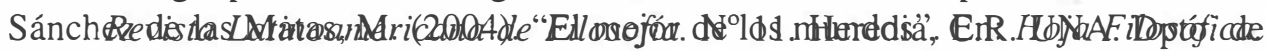
Filosofía.

Sánchez de las Matas, M. (en prensa). La creación de la imperfección o mal metafísico.

Saramago, J. (2005). "El factor dios". Suplemento Los Libros. Revista mensual del Semanario Universidad $\mathrm{n}^{\circ} .173$, junio de 2005.

Weber, M. (1977). Economía y sociedad. Esbozo de sociología comprensiva. Tomo I. México. FCE. 